\title{
Integrating patients' nonmedical status in end-of-life decision making: Structuring communication through 'conferencing"
}

\author{
ROSLYN SORENSEN and RICK IEDEMA
}

\section{Abstract}

This paper considers the nonmedical status of patients in end-of-life decisions. Considering nonmedical factors is not yet routine, particularly in decisions to withhold or withdraw treatment. The paper advocates that nonmedical factors-the capacity and willingness to withstand continuing treatment-are essential to ensure that decisions taken are in the patient's best interest. We argue that including this dimension of patient care not commonly considered gives balance to decisions about continuing treatment where its benefit is diminishing. Drawing on a qualitative study of intensive care nursing in a large public hospital in Sydney, Australia, the paper exemplifies and interprets the tendency of some clinicians to not disclose the medical and nonmedical status to conscious patients, and the environment of mistrust and conflict that can result. We propose a process of 'conferencing'-a regular, inclusive, ongoing, and dynamic process of communication begun early in the patient's admission-to allow multidisciplinary clinicians to manage their differences, agree on patient-care goals, and prepare the patient and their family for the experience of dying. By integrating both medical and nonmedical factors, conferencing becomes the means of enacting and embedding a multidisciplinary, multidimensional approach to endof-life care.

Keywords: death and dying; intensive care; family conferences; communication; decision making; end-of-life care.

Affiliation ( $s$ ): R. Sorensen (University of Technology, Sydney), R. Iedema (University of New South Wales, Sydney)

Correspondence to: Roslyn Sorensen

E-mail: Roslyn.Sorensen@uts.edu.au

\section{Introduction}

The meaning of death and dying is growing as a topic of debate as patients die less in their own homes with close family near, and more in highly technologized, impersonal settings. Personalizing the meaning of death and patients' experience of dying are problematic in regimes of institutional care characterized by the primacy of cure, urgency of decision making, immediacy of action, uncertainty of outcome, and differences of opinion. This growing debate has implications for clinical practice. If death is to regain and retain its meaning as a valid and valuable stage of life, incorporating the nonmedical needs of dying patients-their psychological state, their emotional responses to dying, and their social connectionsbecomes imperative in end-of-life care planning. Integrating and responding to the patient's nonmedical and medical needs will require clinicians to adopt attitudes, values and practices that position the patient at the forefront of decision making. Yet patients are often the least likely to participate in decisions that affect them or to have authority over the type of treatment they receive (Eliott and Olver 2005).

Once a diagnosis of dying emerges, the patient's experience of death becomes a private and personal event predominantly managed by nurses, as curative care recedes in favor of comfort care (Levy 2001). Before the diagnosis, multiple voices begin to emerge to elicit, communicate, and respond to the diverse needs of patients and families as the benefit of treatment diminishes and questions arise about whether to continue or terminate active treatment. Clinicians must therefore learn to master skills and devise processes that engage diverse stakeholders in discussions about what is in the patient's best interests and to constructively manage decision making and care planning in this regard. Engaging and managing here describe processes of mediating competing interests in the event that a patient may prefer to discontinue treatment deemed futile, including where this preference 
goes against the advice of a medical clinician, where family surrogate decision makers are reluctant to agree with the patient's preference to discontinue treatment if they become unconscious, and where multidisciplinary clinical caregivers disagree about where decision authority should lie (Cook et al. 1999; Ellershaw and Ward 2003; Melia 2001).

The experience of people who die in institutions, such as intensive care units (ICUs), often depends on whether those who provide care acknowledge the dying person as an individual (Iedema et al. 2004). The values of the caregiver, their professional orientation, and their internalized experiences of death, both positive and negative, influence attitudes to dying people and shape how death is perceived and care enacted (Block 2001; Van Kleffens et al. 2004). Positioning patients at the forefront of care planning and personalizing their experience of death requires clinical caregivers to reflect upon the meaning of death as an inevitable end to a valued life, and not as a failure of medical technology. Ideally, the dying person and their family will participate in holistic care planning that encompasses the multiple dimensions of the dying person's experience (Stevenson and Scambler 2005; Street and Love 2005). Also ideally, through a process of mutual adjustment (Thompson 1967), treating nurses and doctors acknowledge their attitudes to death and dying, negotiate their differences about what they regard as the appropriate management of dying people, form a consensus of opinion, disclose this information, and plan care accordingly with the patient and their family (Slomka 1992).

Against this background, this paper addresses the organizational implications of achieving 'a good death' within an institutionalized setting (Emanuel and Emanuel 1998) from the perspective of nurses who predominantly attend to the nonmedical needs of dying people. The paper foregrounds the skills and responsibilities that clinical caregivers require to respond appropriately to the needs of dying people and their families, and the organizational processes through which these needs are articulated and met, as routine. We give prominence to a nursing perspective to balance the rich and widely accessible literature on the doctor-patient relationship in end-of-life care with the relatively restricted literature on the nurse-patient relationship. Our research suggests that balancing medical and nonmedical factors at end-oflife will extend understanding of what constitutes patients' best interests as the patient's authority is incorporated within decision processes.

In this paper, we argue that appropriately managing a person's experience of dying is predicated on structured communication through which clinicians can anticipate and meet both the medical and nonmedical needs of dying people and their families, which is, in turn, dependent on preparing all those involved for their experiences and responsibilities at the end of a person's life. Our thesis emerges from a qual- itative study of end-of-life care undertaken in an ICU in a large public acute care hospital, representative of modern institutionalized care for very ill people. Our paper opens with a selected review of the literature, followed by an outline of the study methodology. We then present an analysis and interpretation of selected examples of significant events surrounding the care of dying people. Finally, we discuss the organizational implications for positioning patient and family needs at the center of care.

\section{Contextualizing 'institutional' death and its array of stakeholders}

The experience of dying has become contentious, as people in western societies more frequently die in hospitals (Clarke et al. 2003; Seale 2000). Where death may take its own course if the person dies in their own home, in other settings, such as ICUs, the technology available allows life to be artificially extended and the timing of death to be controlled. The capacity to delay death creates a space within which the circumstances of dying can be arranged to suit the private wishes of individual patients that takes into account their physical, social, emotional, spiritual, or cultural needs (Cook 2001; Klein and Anderson 2002; Parascandola et al. 2002; Schattner and Tal 2002; Street and Love 2005; Valimaki et al. 2001). This space presents an opportunity to attend to the nonmedical care needs of patients and their families contemporaneously with the patient's medical needs that has implications for their practical integration within a regime of end-of-life care.

Rather than harmonizing and synchronizing endof-life care, however, the hope that technology brings can often turn to conflict (Curtis and Burt 2003; Fins and Solomon 2001). By emphasizing curative interventions, delays can occur in preparing the patient and family emotionally and socially for the person's death until after a medical decision of futility is made, or can even exclude it altogether (Harvey 1996). In these circumstances, the pressure on medical clinicians to gain family compliance to withdraw futile treatment from unconscious patients can leave families, and clinicians, confused and distressed (Meier et al. 2001). By excluding nonmedical stakeholders (the patient, their family, and nurses) from progressive discussions that precede medical decisions to withdraw or withhold treatment, a seemingly sudden decision can lead to suspicion and distrust that can compromise the patient's care and the family's experience of their death (Block 2001). High-profile cases played out in the media and a reforming climate in healthcare are bringing a reassessment of the quality of end-of-life care, as power between the clinical professions is being realigned, as consumers' expectations of care are increasing, as confidence in medicine's capacity to cure is eroding, and as an understanding of 
the implications and practicalities of team-based clinical care is emerging (Stevenson and Scambler 2005).

In this regard, it is important that we acknowledge that dying is a difficult event to witness and manage at any time, and that it is especially difficult in a busy ICU accompanied by tension, stress, and experimentation (Harvey 1996). Decisions in this site need to take into account the interests and concerns of at least four groups of stakeholders that predominate in this environment: the patient, their family members, medical and nursing clinicians (Iedema et al. 2004). What emerges in the literature are the contradictions and paradoxes that arise as different stakeholder groups negotiate the sensitivities that surround death and dying, as they attempt to achieve a measure of certainty and hope in an inherently uncertain environment (Harvey 1996). In the absence of processes to bring these contradictions into the open, the calculative actions of stakeholders pursuing their individual interests can lead to disagreement and fracturing of relationships, which can have repercussions for the patient, their family, and the clinicians who attend them.

Trust emerges as a core value in care that places patient interests at the center of decision making. Conscious patients are more likely to remain engaged with the facts of their condition where a prior relationship of trust with caregivers has been established (Seymour et al. 2004). Where trust is absent, and patients act to avoid bad news, clinicians and family members are placed in the difficult position of 'second guessing' just how much patients wish to know, and ultimately taking decisions on their behalf (Farrar 1992; Glaser and Strauss 1965). Paradoxically, the medico-legal climate that prevails in intensive care that gives primacy to curative intervention can undermine trust where the patient's care goals are to cease such intervention (Sprung 1996). Thus goal misalignment can negate patient authority where they are willing and able to remain engaged, and where medical authority strays beyond clinical matters to ethical decisions (Orfali 2004) to limit patient and family involvement in decision making (Slomka 1992).

Placing the patient at the center of care requires clinicians to talk and act across professional, gender, and class boundaries (Stern et al. 1991) and to subsume their personal and professional interests in favor of those of the patient. Paramount here is clinicians' ability to communicate with patients about the very personal act of dying, to understand and respond appropriately to their needs and fears, and to elicit and incorporate their wishes within executable plans. Enabling people to predetermine their preferences about a desired level of intervention in the event of serious illness may help such preferences being adhered to once the person becomes hospitalized (Sullivan 2003; Van Kleffens et al. 2004). The value of such mechanisms appears to again lie in the trust that a dying patient has in their clinician to carry out their wishes
(Mechanic and Meyer 2000), particularly when they are unconscious. While useful in initiating discussions about a sensitive topic, strategies such as advance care planning do not, however, guarantee that a patient's wishes will be respected, or will remain stable, once they become ill (Hammes and Rooney 1998; Nolan 2004; SUPPORT 1996). Indeed, nonrational and erratic decision making may better characterize processes that encourage patient and family involvement, as they attempt to make sense of conflicting and complex information, or where they opt in and out of difficult decisions in heightened emotional states (Eliott and Olver 2005).

Nurses routinely attend to the nonmedical needs of patients and their families as they negotiate these fraught circumstances. However, nurses appear to have relatively less power to recommend or support noninterventionist goals than do their medical counterparts to intervene (Manias and Street 2001; Melia 2001). This powerlessness weakens the professed patient advocacy role espoused by the profession (Vaartio and Leino-Kilpi 2004). Such weakness is registered in the well-being of patients and families, as nurses seek to manage the emotional, social, and other nonmedical needs of dying people within the contradiction of their exclusion from, disagreement with, and expectations of obedience to medical decisions (Chally 1995). Nursing's disagreement with medical decisions to persist with treatment when intervention seems futile is evident from reports of unauthorized tactics, and their concealment, to circumvent medical orders that do not accord with nursing ethics (Leonard et al. 1999). Crucially, nursing's inability to address these problems openly and organizationally (Coombs 2003; Melia 2001) diminishes the chances that patients are offered choices about cure or comfort care, as routine, and hence the opportunity to prepare for their impending death.

Strategies devised to manage stakeholder differences about how to manage patients at end of life often fall short of their objectives. Firstly, in the case of family conferences, a strategy through which stakeholders can, theoretically, discuss and negotiate critical issues in death and dying (Curtis et al. 2001), opinions differ as to their worth. While favored by stakeholders as a means for family members and clinicians to communicate concerns and intentions, their failure to resolve conflict (Abbott et al. 2001; Way et al. 2002) points to the difficulties that medical clinicians experience in gaining trust and exerting their authority, particularly family compliance with decisions to withdraw treatment from unconscious patients (Ahrens et al. 2003; Kirchhoff et al. 2002). In this regard, the exclusion of nursing clinicians from family conferences may preclude the disclosure and open exchange of nonmedical information that may help to inform treatment decisions (Iedema et al. 2005). Secondly, in the case of clinician communication, a similar strategy to improve shortcomings in 
end-of-life care (Azoulay et al. 2000; Baker et al. 2000; Heyland et al. 2002), its profession-specific nature may merely serve to perpetuate differences about appropriate patient care management, and to reinforce professional boundaries (Iedema et al. 2004). This is evident where communication strategies that seek to instill patient and family confidence in medical decisions (Curtis et al. 2002) contradict those of nursing, which emphasize patient empowerment to discuss and determine care goals (Martin 1998). In the absence of structured communication processes to enable differences to be revealed and resolved and agreement negotiated, the divergence in professional attitudes and practices will merely perpetuate shortcomings and preclude patient-centered care.

In what follows, patient-centeredness at end of life is examined through the lens of 'concordance', a process defined as one through which healthcare practitioners and patients work toward a mutual understanding about the therapeutic alliance in which patient participation is made explicit (Stevenson and Scambler 2005). Our analysis suggests that achieving the mutual adjustment that concordance requires means not only redefining relations and encounters between doctors and their patients, but also those between doctors and nurses. By changing relations and realigning power, medical goals take patient goals into account. By extension, we argue that equalizing stakeholder relationships is necessary to allow stakeholders to share decisions, and to disclose information about the patient's full health status and engage in an open exchange about its implications in the context of the patient's values, beliefs, and preferences for care.

\section{Method}

To enhance our understanding of how the nonmedical dimension of patient care is realized in the context of end-of-life care, we undertook a qualitative study to gauge current practice in relation to stakeholder communication in a large intensive care unit in an acute public tertiary hospital in Sydney, Australia. We chose a unit that fulfilled the requirements of a critical case-study site (Flyvbjerg 2001), acknowledged in the field as progressive in intensive care practice and research, and likely to be representative of ICUs in general. Nurses in our study were those most likely to raise the importance of a patient voice in decision making, and to discuss the types of communication that occurred between clinicians, patients, and family members. Our data are drawn from four focus groups comprising a total of thirty nurses with varying levels of experience, that included clinical educators, experienced, less experienced, and trainee nurses, conducted between July 2000 and June 2002. Proceedings were recorded and transcribed. A multidisciplinary team of researchers, which included a policy analyst, a social scientist, and a medical and nursing intensive care clinician, analyzed the data. ${ }^{1}$ Grounded theory was used to elicit themes from the data (Glaser and Strauss 1965, 1968), and a process of discourse analysis was used to examine focus group responses. Informed by the literature, the data were evaluated using the constant comparative method to define and refine themes, domains and items as they emerged, so as to uncover convergent and divergent patterns. A significant theme that emerged was the process of decision making in end-of-life care, the subject of this paper.

\section{Analysis and interpretation}

Nurses are both practitioners of care and observers of practice in ICUs. From their vantage point as intensive carers of individual patients, they are in a position to take a comprehensive view of patient care interaction. Nurses in our study conceptualized this interaction as primarily communication episodes within a continuing but often disconnected series of events that constituted a patient's admission in ICU.

In presenting our analysis, we draw on quotes from the focus groups that are emblematic of the main themes emerging in the context of end-of-life decision making, and accompany them with our interpretation of their relevance in end-of-life care. We structure our analysis in two ways: firstly, by exemplifying problems that respondents identified in communicating about patient care, and secondly, by assessing respondents' proffered solutions. We group our analysis under four headings: communicating with patients; communicating between clinicians; communicating with families; and preparing for end-of-life care.

\subsection{Communicating with patients}

Our analysis opens with a set of excerpts describing the mode of patient care decision making from the nurses' perspective. The first excerpt ([la] below) establishes that nurses expect patients to be consulted about their preferences for treatment, particularly when it is deemed futile. The nurse speaking in Excerpt (1a) questions the failure to do so in this instance. This excerpt indicates that patients are not routinely informed about their prognosis, including specifically a poor prognosis, or about its consequences or the options available in the event that a diagnosis of dying is made. Rather, the medical clinician involved assumed responsibility for the decision to continue treatment, even when it appeared futile. Significant here is the nurse's comment that the patient 'knew he was dying'. The nondisclosure of the prognosis to the patient and the continuation of futile treatment excluded the patient from participating in decisions that affect him and negated opportunities to initiate nonmedical comfort care. This suggests 
that changing from a regime of curative care to one of comfort care becomes contingent on seeking the views of the patient about their preferences for care at key points in the care trajectory. The point at which futility of treatment becomes known is one such key point, when decision authority can be transferred to the patient to choose not to continue with futile treatment that can trigger new care goals, or support the patient as they come to terms with the implications of such news.

(1) a. (Experienced nurse 23/04/02)

Why don't you ask him what do you want to do here? He knew he was dying. Nobody ever said to him, do you want us to stop the treatment?

Two issues arise here that are pertinent to the involvement of patients in decisions about their care. Firstly, not all people in ICU for whom treatment is deemed to be futile are unconscious or require decisions to be made on their behalf. Conscious patients are, potentially, capable of participating in discussions about their care options. Prior to the quote featured, the nurse describes how the attending medical clinician agrees with the family's request to not inform him that treatment has not been successful (experienced nurse 23/04/02). This event reinforces and extends the literature about patient participation in decision making by suggesting that families intervene to shape not only the care of unconscious patients, but also of conscious patients, and that medical personnel collude in this practice.

Secondly, nurses in our study regularly exhibited moral and role conflict to maintain team solidarity in medically initiated decisions, including where they disagreed. The experienced nurse speaking in Excerpt (1b) resolves the dilemma of not consulting the patient when care is deemed futile by discounting the actions of medical clinicians as constrained for medicolegal reasons; they are unable to exercise discretion to terminate treatment, even where futile ('well they feel legally they have to continue'). This nurse disperses moral responsibility on the doctor's behalf: the doctor may not want to continue treatment, but has to, '... because they don't have a formal, legal document.' The nurse in Excerpt (1a) disperses responsibility more broadly to the unit as a whole for not consulting the patient ('Nobody ever said to him'), while simultaneously accepting joint and personal responsibility for the treatment continuing: 'do you want us to stop ...' (Excerpt [1a]).

(1) b. (Experienced nurse 05/03/02)

Well they feel legally that they have to continue because they don't have a formal, legal document.

Neither nurse offered a professional assessment of the appropriateness of continuing treatment on nonmedical grounds, nor did they advocate effectively for the patient's inclusion in the treatment decision.
The nurse speaking in Excerpt (1b) attempted to inform the treating clinician of the (unconscious) patient's preference to cease futile treatment, previously communicated to the nurse and to the patient's husband (experienced nurse 05/03/02). The response of the treating doctor that 'I haven't heard it from her so I have to continue' (experienced nurse 05/03/02) positions the authority for action solely with the doctor and dismisses representation from either the nurse or the patient's family. In this instance, even where the patient's preferences are known and confirmed, medical clinicians can act to override such knowledge. What this excerpt reveals is that not only are systems absent through which medical and nursing clinicians can come together to share information, to discuss differences, and to disclose prognosis with patients and their families, but also absent are the personal and professional values that allow different knowledge and beliefs to be respected and considered, including between members of the treating team. Thus the comprehensive information required for informed decision making remains unarticulated.

\subsection{Communicating between ICU and non-ICU clinicians}

Patients in intensive care units are treated by teams of clinicians constituted by clinicians (nurses, doctors, and allied health) internal to the unit, and also by clinicians from clinical subspecialties external to the unit. The intradisciplinary nature of teamwork, where teams are constituted by members of different medical subspecialties, has received little attention in the literature as an element in the quality of end-of-life care. As with clinicians from different disciplinary backgrounds, medical clinicians from different subspecialty backgrounds who hold different frames of reference will be called upon to pool their diverse knowledge and to come to a clinical consensus about preferred treatment, to prevent the risk of compartmentalizing advice, fragmenting patient care, and fracturing team functioning.

Our analysis has brought to light examples that foreground the importance of intradisciplinary coordination. First is the manner in which medical clinicians with different knowledge bases negotiate primacy of authority. Second is the effect of multiple sources of medical advice on patient and family understanding of care, and the family's capacity to make decisions where advice is complex or conflicting. The nurse speaking in Excerpt (2a) surmises that the power of decision making amongst medical clinicians resides, not in a negotiated outcome having regard to all the facts of the case, but rather to 'the person with the strongest voice'. If a voice of authority is absent, and there is doubt about the patient's prognosis and outcomes of intervention (Excerpt [2a]), the patient can 'drift', if fear of mistakes or attribution of blame brings indecision and inaction. The 
involvement of multiple medical teams from different subspecialties with their own bodies of knowledge about discrete parts of the body, juxtaposed against the holistic treatment goals of intensive care specialists, brings forth a distinct set of issues to be managed in the patient's interest. Uncoordinated information and action will impact on the family's ability to comprehend conflicting advice (implied in Excerpt [2b]) and, ultimately, on their capacity to act as surrogate decision maker. Hence, what appears as illogical action and erratic behavior may also have their origin in professional fragmentation and indecision, exacerbating the fraught circumstances and heightening emotions for patients and families.

(2) a. (Experienced nurse 04/04/01)

Well actually I think the person with the strongest voice wins. And if there is doubt about the dying process the decision is delayed; well then the decision is not even a decision.

(2) b. (Experienced nurse 05/03/02)

Plus also having other teams as well involved. It's not just our intensive care doctors ... like if a family has spoken to the neuro-surgeon they're getting different things from both sides. Like the neuro-surgeon is just dealing with the head, nothing else.

On the basis of this analysis, we contend that multispecialty consensus is a precondition for an orderly process of revealing prognoses to patients and families and their participation in decisions as clinicians provide accurate and comprehensive advice, engage in open dialogue, and guide inquiry. The experienced nurse speaking in Excerpt (3) proposes such a process. The awareness that intervention may be futile becomes a key point and a trigger, not solely for consultation between the intensive care clinician, the patient, and their family, but for the prior comingtogether of multidisciplinary clinicians to present opinions about patient status from their individual frames of reference to reach unanimity of opinion.

(3) (Experienced nurse 04/04/01)

The possibility of discontinuing treatment when the outcome appears hopeless should be discussed by all members of the medical, nursing and allied health staff as well as the patient's admitting team, which is a really good point in this sort of unit. Unanimity must be achieved.

Without organizational processes through which such ideas can be advanced and discussed, the nurse's proposal remains a personal and private opinion. Questions about who has responsibility to call such a meeting, how the multiple disciplines mentioned would contribute, and how a unanimous decision might emerge from encounters such as those described in Excerpts (2a) and (2b) remain unarticulated and unresolved. Equally, how family members come to know of this consensus and to discuss it with the treating clinicians with specialist knowledge is also unclear.

\subsection{Communicating with families}

The importance of effective communication skills to assist clinicians to sensitively discuss end-of-life care issues is also strongly supported by our study. Our analysis reveals, however, that such skills will need to extend well beyond sensitive communication of bad news if the comprehensive needs of family members are to be appropriately managed and met. Hence, routine caregiving skills should encompass providing relevant, adequate, and accurate medical and nonmedical information about the condition of the patient, educating families about the role of surrogate decision makers and the consequences of particular interventions, and supporting them in the patient's transition through the stages of dying and death, as well as supporting families through their own emotional transition.

A factor that emerged from focus group discussion about providing adequate support to families at times of death, particularly the family's access to relevant, adequate, and accurate information, concerned interpersonal dynamics and the quality of the relationship between nursing and medical clinicians. Our study routinely revealed the stress, discomfort, and conflict that both medical and nursing clinicians experienced from a family's need for information and support. Of necessity, busy medical clinicians must impose limits on their availability to family members. In Excerpt (4) they do so by '(speaking) to the (one, particular) person that needs to be spoken to-the next of kin'. The nurse who speaks describes the confusion and dissatisfaction that can arise for all involved when roles, responsibilities and processes for communication and support are not established or clear. The risk that some family members may feel excluded from discussions or that information is withheld from them, may impact negatively on their understanding of events and help create the conditions where suspicion arises and trust is lost.

\section{(4) (Less experienced nurse 05/02/02)}

Sometimes you're the middle person and I really get annoyed about that because it happened to me last week and they're asking me things and then they want to talk to the doctor and the doctor says no I've spoken to the person that needs to be spoken to, the next of kin, I'm not speaking to anybody else and they're looking at me wanting me to signal the doctor and I think, oh I'm the middle man here and I don't like this.

Both doctors and nurses in this unit agreed that nurses play an important information-giving and family-support role (Iedema et al. 2005). What is not 
clear is how nurses come to know of the clinical information and decisions that will allow them to play this role. What is implied in this excerpt is that collective team-based information-generating. consensus-building, and decision-making processes, which include formalizing an information-giving role. underpin nurses' capacity to support family members through their confronting experiences, and potentially also decrease pressure on medical clinicians' time.

Paradoxically, it appears that the pressure on medical clinicians to gain closure when treatment is futile constrains nurses from enacting an informationgiving role that could potentially ameliorate such pressure. Nursing exclusion from family conferences called to inform families of futility and to gain consent to withdrawal or withholding of treatment, implied in Excerpts (5a) and (5b) below, reduced the nurses' capacity to support families and maintain consistency of information and action ('I've lost the plot'). Where nurses were included in conferences, contributing their knowledge often became an act of assertion ('I always need to put in my five cents" worth") - not as a central part of the conference, but "at the end of it'. Even though nurses attempted to position themselves as part of the clinical team (as suggested in Excerpt [1a] above by the use of the collective pronoun ' $u s^{\prime}$ ), the excerpts below ([5a] and [5b]) indicate that medical clinicians, including registrars (trainee medical specialists), do not share this view. Nurses here are not valued team members with responsibility and authority to interpret medical information to patients and families or to initiate specialist skills when intervention is deemed futile, but are marginalized to the medical priorities of intervention and termination.

(5) a. (Experienced nurse 07/02/02)

I find that some of the registrars tend to sneak off and have family conferences on their own. And then I've lost the plot.

(5) b. (Experienced nurse 05/03/02)

And I feel that at every family conference anyway, I always need to put in my five cents' worth ... at the end of it.

The potential for family conferences to become a therapeutic device for family members to confront the forthcoming death of their family member through dialogue is raised in Excerpts (6a) and (6b) below. In describing the difficulties medical clinicians face in breaking bad news, the nurse speaking in Excerpt (6a) illustrates the miscommunication that can arise from the absence of clear and unambiguous messages. The co-construction of misunderstanding becomes possible, as each party to the communication event 'hedge(s)' bad news. Here, the opportunity to confront and manage the "fear of telling" and "fear of knowing' as barriers to effective communication is foregone. In our example, neither medical clinicians, nor, presumably, nursing clinicians, were in a position to assess, manage, and support families confronted with distressing news, and on which their understanding of the patient's progression from illness to dying to death would be based. 'Decisiveness' ("this is what we're going to do', Excerpt [6b]) becomes the means through which the time and discomfort of honest communication and its emotional consequences are avoided.

(6) a. (Experienced nurse 23/04/02)

but human nature being what it is I don't think people directly hear that because they're frightened to know. So you get this sort of ... hedgy thing, which you have to do of course because you re dealing with people's feelings ...

(6) b. (Intermediate nurse 12/02/02)

I think letting them talk, letting them express their feelings, because sometimes I feel that when you go to a family conference the doctor says this, this and this and then-this is what we go going to do. And they're too scared to ask because the doctor said this is what we're going to do.

Family conferences, generally held once medical treatment is deemed futile, are often the first time that family members become aware of the nonreversible nature of the patient's condition. It is unlikely in these circumstances that families will be able to absorb distressing information and consent to withdraw treatment simultaneously. To view family conferences solely as an instrument for gaining informed consent is to miss their dynamic educational and therapeutic effect in preparing patients and families, and clinicians, for their responsibilities by sharing information, rehearsing responses, resolving queries, correcting misunderstandings, and negotiating care decisions, including, importantly, comfort care. We turn to our final segment of analysis to consider ways that stakeholders might prepare for their experiences and responsibilities at end of life.

\section{Preparing for end-of-life care}

The uncertainty within which intensive care is practiced has repercussions for the care of patients and their families and the legal position of clinicians. Preparing patients and families for the confronting experience of death, and preparing clinicians for their roles in curative and comfort care, underpins quality of care at end of life including appropriate decision making about whether treatment should be continued or terminated and who should participate in such decisions. Firstly, we consider how the preparation of patients and family members for the events they may experience can solidify as routine practice. Secondly. we consider the preparation of clinicians in this regard, and the transformation of end-of-life care from 
a series of unstructured, cascading events (Slomka 1992) to an ordered, anticipated, integrated set of practices that orient to connecting knowledge, decisions, actions, and outcomes.

\subsection{Preparing patients}

In preparing a patient for the possibility that treatment may not be successful, nurses emphasized timing as key. The nurse speaking in Excerpt (7a) advances patient admission to the ward as the time when rapport has been established, especially with relatives. Early acknowledgement of the possibility of death initiates the family's emotional and social transition in parallel with the patient's biological deterioration and the loss of hope that this entails. Preparation obviates the element of surprise and creates the conditions within which patients themselves can acknowledge, articulate, and accommodate, anticipate even, 'a bleak picture' (Excerpt [7b]). Hence, disclosure of patients' deteriorating prognoses and preparation for this eventuality become prerequisite events that enable patients to formulate their own treatment goals (Excerpt [7b]: 'they're empowered to say, OK well look ...'), and to seek family compliance (Excerpt [7c]: 'and she turned around to them and she said to them: no'). This early and systematic inclusion of family members in conference processes as a means to engender compliance to patient care goals is also taken up in Excerpts (8a) and (8b) further below.

(7) a. (Nurse educator 31/05/01)

... when we admit them we are angels ... they are so appreciative and that's when it's important (to begin discussions) because you have established a rapport with that relative ... that's when those conversations should take place.

(7) b. (Experienced nurse 05/03/02)

... that's empowering them, so when they come-if they do end up in the intensive care unit then they're empowered to say to the staff well I know that from here on the picture is pretty bleak. And then I guess the clinical staff can reinforce that if that's the case. And then they're empowered to say, OK well look...

(7) c. (Less experienced nurse 05/02/02)

I think having everyone prepared. I remember a cancer patient, she said-the daughters kept saying-no come on, we need to do this, we need to do that, and she turned around to them and she said to them: no, I've had enough. I just want to finish it. And she was prepared.

\subsection{Preparing families}

The nurse speaking in Excerpt (8a) countenances an active role familiarizing families early about the even- tualities of intensive care. In the types of situations described here, futility disputes might be expected to occur, where the family is required to consent to withdrawal of treatment at the same time as hearing that their loved one is beyond cure. The nurse speaking in Excerpt (8a) states the imperative for discussions with family members to occur early, certainly well before the day that treatment is to be discontinued, extended by the nurse speaking in Excerpt (8b) to become a 'standardised thing ... at least once a day, or ... every shift'. In current practice, nurses are not in a position to know of clinical decisions so as to enact such a role. To do so, nurses would be required to routinely and consistently participate in and contribute to information-giving and decision-making processes, such as ward rounds, clinical meetings, and family conferences, and to be given commensurate decision authority.

\section{(8) a. (Experienced nurse 05/02/02)}

I think that's something we could get better at, talking to the family early enough. A lot of the time it's far too late, and we'll talk to them on the day that the person is going to die.

(8) b. (Experienced nurse 05/03/02)

I think as far as communication with family that could be a standardised thing, like, that needs to happen at least once a day and maybe even sometimes, every shift.

To manage the multiple medical and nonmedical dimensions of end-of-life care, clinicians and clinical managers will be called upon to change existing communication systems and interpersonal relations between intra- and interdisciplinary clinicians and between clinicians, patients, and family members. As presently constituted, family conferences are limited in the role they can play in communicating about life-and-death issues; but as a structured process of embedded routine practice, they become the systematic means through which patients and family members are prepared for the experience of death (Becker and Knudson 2003). Formalizing nursing clinicians' nonmedical support role becomes pivotal in setting the groundwork for conscious patients to review their life, to envision their death, and to rehearse conversations and instill their wishes with family members where their condition is beyond cure.

\subsection{Preparing clinicians}

We take up the theme in Excerpt (9) of preparing clinicians to shape their practice to forecast and manage patient and family expectations and experiences as they unfold. End-of-life discussions can be anticipated, phased, structured, and therefore planned (Barton et al. 2005). The experienced nurse speaking in Excerpt (9) describes the processes needed to 
achieve 'a nice death'. In her view, intensive care is not, by necessity, reactive: curative care can be logically planned and organized; care options can be applied in an ordered and systematic manner; outcomes can be reviewed before proceeding to the next step. Through continual discussion, the family is informed and prepared if the plan 'doesn't work'. Trust and cooperation continue to be built as families witness and perceive coherence of planning and thoroughness of action that reinforce confidence that everything possible was done. Managing doubt and uncertainty in this way allows the next stage to unfold: family members can experience social closure ('a chance to say goodbye'); nursing staff can experience clinical closure ('a nice death, not a traumatic (one)', experienced nurse $05 / 03 / 02$ ). Here, the agreed plan becomes the embodiment of trust and accountability in the form of specific expectations and personal behaviors (Stevenson and Scambler 2005) and potentially mutual satisfaction in knowing that the best job has been done.

(9) (Experienced nurse 05/03/02)

A pre-plan. We've done what we can. You know very quickly over a space of two months. We've done that; it hasn't worked. And we've talked to the family all the way through so they're very up to date about what our thoughts are, what's going on. what the plan is if this doesn't work. They get a chance to say goodbye as well as knowing what could have been done has been done.

Preparing patients, families, and clinicians in this way for their experiences and responsibilities at end of life begins at time of admission to ICU, although feasibly earlier in emergency departments and wards, and continues throughout the patient's episode of care. Preparation allows patients to anticipate and manage the disclosure of bad news in their own way, and patient-guided discussion with relatives, augmented by routine information sharing by clinicians, allows family members to keep pace with the logic of action as events unfold, and to maintain decision-making involvement as clinicians openly disclose and manage the fluctuations in a patient's condition, the uncertainty of treatment outcomes, and the implications that this brings for the patient and their family. We go on to outline structured communication in the context of end-of-life care and how it might be achieved organizationally.

\section{Concluding discussion}

Nurses in our analysis characterized intensive care as often uncertain, chaotic, and urgent, and constituted by empowered doctors. disempowered nurses, and unempowered patients and families. Through concordance, we propose a process through which these stakeholders can begin to achieve a measure of mutual understanding about a therapeutic alliance constituted by multiple caregivers and in which patient interests are central and explicit. This process requires that the attitudes and practices of clinical caregivers and values and preferences of patients are known so as to guide decisions about patient care. This requirement assumes that doctors, nurses, and patients, and their families if the patient is unconscious. participate equally in sharing knowledge and making decisions.

On the basis of our analysis and our review of the literature. we advocate a process of structured communication for managing a patient's illness trajectory, initiated at key points during the patient's admission. This process would include, firstly, a patient conference initiated on admission that includes family members to prepare them for the eventualities of intensive care, including their responsibilities in the event that the patient's condition worsens, and to inform them of clinician roles, particularly differentiating the cure role of medicine and the comfort, information-giving. and support roles of nursing. Secondly, clinical conferences would continue through the daily ward round with appropriate medical and nursing participation that include a formalized nursing responsibility to obtain and provide updated information to the patient on their health status. Thirdly, a clinical conference would be convened with appropriate medical and nursing participation to pool knowledge and reach clinical consensus where there is a medical or nursing alert that the patient's condition has changed and the patient is dying. Fourthly, a patient conference would be convened to disclose information about their condition, to outline and openly discuss options, and to formulate a care plan that links back to the initial preparatory patient conference.

Our analysis suggests three sticking points where problems regularly occur in end-of-life care planning. These are, firstly, when nurses are alerted to the possibility that patients are dying while curative treatment is still active; secondly, when medical specialists disagree about a prognosis of dring; and thirdly, when family members are unable to agree to terminate active treatment. The proposed process will not eliminate the different opinions that arise as people die, nor should it; it does attempt to manage known key points in the patient's trajectory so as to anticipate and prepare for patient and family needs to reduce the risk of unmanaged differences and the consequences of conflict.

While modern medical technology saves the lives of many patients who might otherwise have died, not all patients admitted to intensive care units have this outcome. Where, traditionally, medical intervention to cure or salvage patients has had primacy in end-oflife care, as knowledge about the dying process in institutional settings grows, models of care are shifting to take nonmedical needs into account. Integrating the medical and nonmedical needs of patients and 
families poses a dilemma for caregivers, within the environment of uncertainty, immediacy of action, and conflicting opinions in which care is delivered. Appropriately responding to the needs of dying people and their families, particularly in the space created once a diagnosis of dying is made, is not the action of the moment, but rather the consequence of trust and knowledge developed over time through inclusive and cooperative relationships.

Integrating these multiple dimensions of care will cut across well-established dynamics between stakeholder groups, such as medical autonomy, nursing deference, patient passivity, family resistance, and legal prerogative. Left unattended, these taken-forgranted attitudes and practices will serve merely to entrench the status quo. Achieving concordance, by placing the patient at the center of care through information and decision sharing, is predicated upon forming new relationships within and between medical and nursing caregivers, and between clinicians, patients, and family members. These new relationships will involve clinicians in restructuring, relearning, and realigning care roles, responsibilities, and identities systemically, interpersonally, and personally. Restructuring requires medical and nursing clinicians to come together cooperatively as a community of practice (Wenger 1998) to pool information about the patient's condition as it unfolds, to forge clinical consensus, to regularly familiarize patients and family members with intensive care practice, and to encourage participation in decision making, including surrogate decision makers, so as to develop agreed plans of care. As a collective record of agreement and expectations, relationships of trust become embodied in these plans, and as written records, become the means to account for actions and to review care outcomes. Through this structured team collaboration, relearning takes place as clinicians reflect on the goals of care and their responsibility in achieving them. Realigning identities as equal team members occurs as clinicians begin to transform from autonomous actors into multidisciplinary team members, accepting of equal but different knowledge.

We advance the concept of 'conferencing' as a comprehensive term to define this ongoing process of restructuring and realignment. Conferencing requires acceptance at an individual and systems level that structural and organizational change is valid, feasible, and necessary. The changes that underpin the concept may be difficult to achieve in practice, where patient and practitioner goals are distorted. But practice can be improved through a balancing of professional expertise and patient viewpoint as doctors and nurses understand and enact their collective accountability to the populations they serve.

Such desirable behaviors do not occur randomly and are not the outcome of 'some kind of ideal speech situation' (Stevenson and Scambler 2005). If actions are intended to achieve agreement through trusting relationships, they must become a routine part of patient care (Ellershaw et al. 1997; Ellershaw and Ward 2003; Slomka 1992; Way et al. 2002). In end-of-life care, this routinizing occurs as multiple stakeholders negotiate the timing and circumstances of death, which are no longer arbitrary events but take the form of patterned trajectories of illness (Murray et al. 2005). Over the course of a person's illness, these stakeholders come together at key points in the patient's illness trajectory to discuss prognoses, reveal uncertainties, negotiate differences, and, ultimately, agree on care goals. The process of structured communication at end of life provides for continual review by multidisciplinary clinicians, and thereby can maintain its core aims of preparing patients, families, and clinicians for their roles in end-of-life care, forming a consensus about patient prognosis, disclosing early information to patients and families where treatment is potentially futile, and eliciting and adhering to patient values and preferences. These ongoing reviews by communities of practice become the bases for triggering, devising, and enacting practices that are ethically and practically defensible and that underpin the harmonious and routine management of multiple stakeholder interests at end of life.

Reconceptualized thus, (family) conferences become the mechanism through which stakeholders in end-of-life care can plan and enact an integrated multidisciplinary, multidimensional, multilevel mode of care. As structured communication, end-of-life conferences are predicated on managing the interests of multiple stakeholders, as the awareness of dying emerges and the circumstances of death are acknowledged, negotiated, and planned around the wishes of individual patients and their families. We denote this emergent, participative, interactive, and ongoing process as 'conferencing' - the visible and analyzable means through which clinicians, patients, and family members, collectively, can envision the future (Engestrom et al. 2003) and prepare for it.

\section{Notes}

* This research was funded by the Australian Research Council and South West Sydney Area Health Service.

1. We thank Pieter Degeling, Ken Hillman, Elizabeth Turnbull, and Arthas Flabouris for their contribution to the research.

\section{References}

Abbott, K., Sago, J., Breen, C., Abernathy, A., and Tulsky, J. (2001). Families looking back: One year after discussion of withdrawal or withholding of life-sustaining support. Critical Care Medicine 29 (1): 197-201.

Ahrens, T., Yancey, V., and Kollef, M. (2003). Improving family communications at the end of life: Implications for 
length of stay in the intensive care unit and resource use American Journal of Critical Care 12 (4): 317-324.

Azoulay, E., Chevret, S., Leleu, G., Pochard, F., Barboteu, M., Adrie, C., et al. (2000). Half the families of intensive care unit patients experience inadequate communication with physicians. Critical Care Medicine 28 (8): 3044-3049.

Baker, R., Wu, A. H., Teno, J. M., Kreling, B., Damiano, A., Rubin, H., et al. (2000). Family satisfaction with end-of-life care in seriously ill hospitalized adults. Journal of the American Geriatrics Society 48 (5): S61-S69.

Barton, E., Aldridge, M., Trimble, T., and Vidovic, J. (2005). Structure and variation in end-of-life discussions in the surgical intensive care unit. Communication \& Medicine 2 (1): 3-20.

Becker, S. and Knudson, R. (2003). Visions of the dead: Imagination and mourning. Death Studies 27 (8): 691.

Block, S. (2001). Helping the clinician cope with death in the ICU. In Managing Death in the ICU, J. Curtis and G. Rubenfeld (eds.), 183-192. Oxford: Oxford University Press.

Chally, P. (1995). Nursing research: Moral decision making by nurses in intensive care. Plastic Surgical Nursing 15 (2): $120-124$.

Clarke, E., Curtis, J., Luce, J., Levy, M., Danis, M., Nelson, J., et al. (2003). Quality indicators for end-of-life care in the intensive care unit. Critical Care Medicine 31: 2255-2262.

Cook, D. (2001). Patient autonomy versus paternalism. Critical Care Medicine 29 (2 Suppl): N24-N25.

Cook, D., Giacomini, M., Johnson, N., and Willms, D. (1999). Life support in the intensive care unit: A qualitative investigation of technological purposes. Canadian Medical Association Journal 161 (9): 1109-1113.

Coombs, M. (2003). Power and conflict in intensive care clinical decision making. Intensive and Critical Care Nursing 19: $125-135$

Curtis, J. and Burt, R. (2003). Why are critical care clinicians so powerfully distressed by family demands for futile care? Journal of Critical Care 18 (1): 22-24.

Curtis, J., Engelberg, R., Wenrich, M., Nielsen, E., Shannon, S., Treece, P., et al. (2002). Studying communication about end-of-life care during the ICU family conference: Development of a framework. Journal of Critical Care 17 (3): 147160.

Curtis, J., Patrick, D., Shannon, S., Treece, P., Engelberg, R., and Rubenfeld, G. (2001). The family conference as a focus to improve communication about end-of-life care in the intensive care unit: Opportunities for improvement. Critical Care Medicine 29 (2): N26-N33.

Eliott, J. and Olver, I. (2005). End-of-life decision making is more than rational. Communication \& Medicine 2 (1): 21 34.

Ellershaw, J., Foster, A., Murphy, D., Shea, T., and Overill, S. (1997). Developing an integrated care pathway for the dying patient. European Journal of Palliative Care 4 (6): 203-207.

Ellershaw, J. and Ward, C. (2003). Care of the dying patient: The last hours or days of life. British Medical Journal 326: 30-34.

Emanuel, E. J. and Emanuel, L. L. (1998). The promise of a good death. The Lancet 351: SII21.

Engestrom, Y., Engestrom, R., and Kerosuo, H. (2003). The discursive construction of collaborative care. Applied Linguistics 24 (3): 286-315.

Farrar, A. (1992). How much do they want to know? Communicating with dying patients. Professional Nurse (June): 606-610.
Fins, J. and Solomon, M. (2001). Communication in intensive care settings: The challenge of futility disputes. Critical Care Medicine 29 (2): N10-N15.

Flyvbjerg, B. (2001). Making Social Science Matter: Why Social Science Fails and How It Can Succeed Again. Cambridge: Cambridge University Press.

Glaser, B. and Strauss, A. (1965). Awareness of Dying. London: Weidenfeld and Nicholson.

-(1968). The Discovery of Grounded Theory: Strategies for Qualitative Research. London: Weidenfeld and Nicholson.

Hammes, B. J. and Rooney, B. L. (1998). Death and end-of-life planning in one Midwestern community. Archives of Internal Medicine 158 (4): 383-390.

Harvey, J. (1996). Achieving the indeterminate: Accomplishing degrees of certainty in life and death situations. The Sociological Review 44 (1): 78-98.

Heyland, D., Rocker, G., Dodek, P., Kutsogiannis, D., Konopad, R., Cook, D., et al. (2002). Family satisfaction with care in the intensive care unit: Results of a multicenter study. Critical Care Medicine 30 (7): 1413-1418.

Iedema, R., Sorensen, R., Braithwaite, J., Flabouris, A., and Turnbull, E. (2005). The teleo-affective limits of end-of-life care in the intensive care unit. Social Science \& Medicine 60 (4): 845-857.

ledema, R., Sorensen, R., Braithwaite, J., and Turnbull, E. (2004). Speaking about dying in the intensive care unit, and its implications for multidisciplinary end-of-life care. Communication \& Medicine 1 (1): 85-97.

Kirchhoff, K., Walker, L., Hutton, A., Spuhler, V., Vaughan Cole, B., and Clemmer, T. (2002). The vortex: Families' experiences with death in the intensive care unit. American Journal of Critical Care 11 (3): 200-209.

Klein, A. W. and Anderson, R. J. (2002). Patient autonomy: When do physicians intervene? Obstetrics \& Gynecology 99 (1): $S 29$.

Leonard, C., Mohindra, V., Ruoss, S., Doyle, R., and Raffin, T. (1999). European life-support questionnaire. Critical Care Medicine 27: 1686-1687.

Levy, M. M. (2001). Compassionate end-of-life care in the in tensive care unit. Critical Care Medicine 29 (2 Suppl): N1.

Manias, E. and Street, A. (2001). Nurse-doctor interactions during critical care ward rounds. Journal of Critical Care Nursing 10: 442-450.

Martin, G. (1998). Empowerment of dying patients: The strategies and barriers to patient autonomy. Journal of Advanced Nursing 28 (4): 737-744.

Mechanic, D. and Meyer, S. (2000). Concepts of trust among patients with serious illness. Social Science \& Medicine 51: 657-668.

Meier, D. E., Back, A. L., and Morrison, R. S. (2001). The inner life of physicians and care of the seriously ill. Journal of the American Medical Association 286 (23): 3007-3014.

Melia, K. (2001). Ethical issues and the importance of consensus for the intensive care team. Social Science \& Medicine 53 (6): 707-719.

Murray, S., Kendall, M., Boyd, K., and Sheikh, A. (2005). Illness trajectories and palliative care. British Medical Journal 330: $1007-1011$.

Nolan, M. (2004). Could lack of clarity in written advance directives contribute to their ineffectiveness? A study of the content of written advance directives. Applied Nursing Research 16 (1): 65-69.

Orfali, K. (2004). Parental role in medical decision-making: Fact or fiction? A comparative study of ethical dilemmas in 
French and American neonatal intensive care units. Social Science \& Medicine 58 (10): 2009-2022.

Parascandola, M., Hawkins, J., and Danis, M. (2002). Patient autonomy and the challenge of clinical uncertainty. Kennedy Institute of Ethics Journal 12 (3): 245-264.

Schattner, A. and Tal, M. (2002). Truth telling and patient autonomy: The patient's point of view. The American Journal of Medicine 113 (1): 66-69.

Seale, C. (2000). Changing patterns of death and dying. Social Science and Medicine 51: 917-930.

Seymour, J. E., Gott, M., Bellamy, G., Ahmedzai, S. H., and Clark, D. (2004). Planning for the end of life: The views of older people about advance care statements. Social Science \& Medicine 59 (1): 57-68.

Slomka, J. (1992). The negotiation of death: Clinical decision making at the end of life. Social Science \& Medicine 35 (3): 251-259.

Sprung, C. L. (1996). Judicial intervention in medical decisionmaking. Critical Care Medicine 24: 730-732.

Stern, H., Stroth, S., Fiser, D., Cromwell, E., McCarthy, S., and Prince, M. (1991). Communication, decision making, and perception of nursing roles in a pediatric intensive care unit. Critical Care Nursing Quarterly 14 (3): 56-68.

Stevenson, F. and Scambler, G. (2005). The relationship between medicine and the public: The challenge of concordance. Health: An Interdisciplinary Journal for the Social Study of Health, Illness and Medicine 9 (1): 5-21.

Street, A. and Love, A. (2005). Dimensions of privacy in palliative care: Views of health professionals. Social Science \& Medicine 60 (8): 1795-1804.

Sullivan, M. (2003). The new subjective medicine: Taking the patient's point of view on health care and health. Social Science and Medicine 56: 1595-1604.

SUPPORT (1996). A controlled trial to improve care for seriously ill hospitalized patients: The study to understand prognoses and preferences for outcomes and risks of treatments. Journal of the American Medical Association 274: 1591-1598.
Thompson, J. (1967). Organizations in Action. New York: McGraw-Hill.

Vaartio, H. and Leino-Kilpi, H. (2004). Nursing advocacy-A review of the empirical research 1990-2003. International Journal of Nursing Studies 42 (6): 705-714.

Valimaki, M., Leino-Kilpi, H., Antila, M., Myllyla, B., Dassen, T., Gasull, M., et al. (2001). Patient autonomy in surgical care. Hoitotiede 13 (3): 155-166.

Van Kleffens, T., van Bfaarsen, B., and van Leeuwen, E. (2004). The medical practice of patient autonomy and cancer treatment refusals: A patients' and physicians' perspective. Social Science \& Medicine 58 (11): 2325-2336.

Way, J., Back, A., and Curtis, J. (2002). Withdrawing life support and resolution of conflict with families. British Medical Journal 327: 1342-1345.

Wenger, E. (1998). Communities of Practice: Learning, Meaning and Identity. Cambridge: Cambridge University Press.

Rosiyn Sorensen is Senior Lecturer at the Centre for Health Services Management in the Faculty of Nursing, Midwifery and Health at the University of Technology, Sydney. She teaches in the areas of health service organization and management. Her research interests lie in health policy development and implementation, health service governance and accountability, and clinical process management. Address for correspondence: Centre for Health Services Management, Faculty of Nursing, Midwifery and Health, University of Technology, Sydney NSW 2000, Australia. E-mail: Roslyn.Sorensen@uts.edu.au

Rick Iedema is Associate Professor in the School of Public Health and Community Medicine and Deputy Director at the Centre for Clinical Governance Research at the University of New South Wales. He is currently involved in four Australian Research Council funded projects deploying discourse-oriented, video-ethnographic investigations to illuminate the organization and enactment of safety and quality in acute care. He has published widely across the areas of discourse analysis, health services research, and organization studies. 